\title{
Methods for estimating a critical value for determining the freshwater/estuarine habitat residence of American eels from otolith Sr:Ca data
}

\author{
B.M. Jessop ${ }^{\text {a,* }}$, J.C. Shiao ${ }^{\text {b }}$, Y. Iizuka ${ }^{c}$ \\ ${ }^{a}$ Department of Fisheries and Oceans, Bedford Institute of Oceanography, PO Box 1006, Dartmouth, Nova Scotia B2Y 4A2, Canada \\ ${ }^{\mathrm{b}}$ Institute of Oceanography, College of Science, National Taiwan University, Taipei, Taiwan 10617, ROC \\ ${ }^{c}$ Institute of Earth Sciences, Academia Sinica, Nankang, Taipei, Taiwan 11529, ROC
}

\section{A R T I C L E I N F O}

Article history:

Received 1 August 2012

Accepted 9 September 2013

Available online 25 September 2013

\section{Keywords:}

American eel

otolith

Sr:Ca ratios

linear discriminant analysis

diadromous fish

\begin{abstract}
A B S T R A C T
Linear discriminant analysis (LDA) and habitat discrimination critical value (HDCV) methods are alternatives for evaluating the migratory history, such as the proportion of residence in freshwater (\%fwr) and estuarine/marine habitats, of individual American eels (Anguilla rostrata) via the analysis of otolith Sr:Ca data. The LDA process requires Sr:Ca data from both freshwater and estuarine/marine groups while the mean $+c S D$ method requires only a freshwater standard. For the two group (freshwater, estuarine/ marine), single predictor variable (Sr:Ca) case, the LDA process defaults to Fisher's linear discriminant where the HDCV equals the average of the group mean $\mathrm{Sr}$ :Ca values. The difference between freshwater and estuarine resident eel mean otolith Sr:Ca values, based on 13 published studies and the current study $(n=14)$, decreased with increasing freshwater group otolith mean $(r=0.80, p<0.001)$, reflecting a relatively constant estuarine group mean $(r=0.38, p=0.17)$. A process is proposed for estimating a HDCV from freshwater group otolith Sr:Ca mean and SD values based on empirical linear relations between the LDA, HDCV and freshwater mean $(n=14, r=0.90, p<0.0001)$ and $c$ and SD $(n=14, r=-0.89$, $p<0.0001)$ from the equation HDCV $=$ mean $+c S D$. Variation in the sample sizes of otolith Sr:Ca values used in the discriminant process of estimating a HDCV, while statistically significant, had trivial effect sizes that were likely of little biological consequence. However, larger sample sizes are preferred over smaller sample sizes. Estimates of \%fwr increased with increases in the HDCV. Differences in \%fwr estimates over a range of HDCVs were highly statistically significant and effect sizes increased with increased HDCV difference. As HDCV levels increased, growth rate estimates increased for a given \%fwr value. A HDCV difference of $\leq 0.5 \times 10^{-3}$ produced a small effect size. Accurate estimation of a HDCV is fundamental to the assessment of the habitat residence and inter-habitat movement of American eels and perhaps of other diadromous fishes and helps minimize bias in dependent estimates of other useful statistics such as the percentage of freshwater residence (\%fwr) and growth rate.
\end{abstract}

(c) 2013 Elsevier Ltd. All rights reserved.

\section{Introduction}

Measurements of otolith Sr:Ca ratios from core to edge have been used to investigate the habitat residence (freshwater, saline water) and inter-habitat movement of temperate-zone anguillid eels (Anguilla anguilla, Anguilla rostrata, Anguilla japonica; reviewed by Daverat et al., 2006; Jessop et al., 2008; Anguilla australis, Anguilla dieffenbachia; Arai et al., 2004), tropic-zone anguillids (Anguilla marmorata, Anguilla bicolor bicolor; Chino and Arai,

\footnotetext{
* Corresponding author.

E-mail address: welljess@ns.sympatico.ca (B.M. Jessop).
}

2010a,b,c) and a wide variety of other diadromous fishes such as rainbow smelt (Osmerus mordax; Bradbury et al., 2008), American shad (Alosa sapidissima; Walther and Thorrold, 2008), barramundi (Lates calcifer; McCulloch et al., 2005), and galaxia (Galaxias maculates; Hale and Swearer, 2008). The habitat residence and interhabitat migratory history of individual eels has been examined by otolith microchemistry consequent to the positive relations between ambient salinity and Sr:Ca ratio and the otolith Sr:Ca ratio (Tzeng, 1996; Campana, 1999; Daverat et al., 2005; Tabouret et al., 2010). The ambient water Sr:Ca values are more highly correlated with otolith Sr:Ca values than is salinity for freshwater and diadromous fishes (Kraus and Secor, 2004; Brown and Severin, 2009). The assumptions underlying the use of otolith Sr:Ca profile analysis 
to examine life-history variation within a population and to describe movements between habitats have been reviewed by Elsdon et al. (2008) e.g., that individuals can be classified into different groups on the basis of otolith chemistry, that otolith chemistry changes predictably in response to environmental parameters, and that group profiles are representative of all potential individual profiles consistent with the group. Fish otoliths effectively integrate the effects of temporal variability in ambient $\mathrm{Sr}: \mathrm{Ca}$ over the time (30+ days, Jessop et al., 2002) taken to deposit the $\mathrm{Sr}:$ Ca value represented by the spatial resolution of the analytical method (e.g., $5 \mu \mathrm{m}$ ) (Walther and Limburg, 2012). Freshwater resident fish typically have lower $\mathrm{Sr}$ :Ca levels with lower variability than do estuarine fishes (Brown and Severin, 2009).

The description of life-history variation from otolith $\mathrm{Sr}: \mathrm{Ca}$ profile analysis has progressed from simply describing the presence of different habitat groups (saltwater, estuarine, freshwater) (Tzeng et al., 1997; Kotake et al., 2005; Daverat and Tomás, 2006; Thibault et al., 2007) to quantifying the proportion of each group, given appropriate fish sample sizes (Tsukamoto and Arai, 2001; Tzeng et al., 2002; Daverat et al., 2006). A further extension quantifies the proportion of individual fish residence in each habitat based on the proportion of Sr:Ca values along a transect from elver check to edge that correspond to the appropriate habitat group. For example, the percentage (proportion) of freshwater residence (\%fwr) is based upon the percentage of otolith Sr:Ca values that exceed a critical or habitat discrimination value (HDCV) that distinguishes freshwater residence from estuarine/marine residence (Jessop et al., 2004, 2006, 2008; Elsdon and Gillanders, 2005). The common qualitative approach to otolith Sr:Ca transect interpretation and life-history classification based on a visual interpretation of otolith $\mathrm{Sr}$ :Ca values and trends implicitly infers a HDCV, although such values are often not explicitly given. The critical value concept has also been termed "index of seawater residence" (Tsukamoto and Arai, 2001), "residence discrimination criterion" (Tzeng et al., 2002), "Sr:Ca reference value" (Daverat and Tomás, 2006), and "threshold value" (Thibault et al., 2007) amongst other terms. An analogous HDCV can be defined to separate estuarine and marine habitats (Tsukamoto and Arai, 2001; Daverat et al., 2005; Tabouret et al., 2010; Jessop et al., 2011).

The number of excursions from freshwater to saline waters and back by an individual fish has been estimated by the number of groups of contiguous otolith $\mathrm{Sr}$ :Ca values greater than the HDCV (Jessop et al., 2006; Lamson et al., 2006). Whether singleton Sr:Ca values above or below the HDCV represent true habitat transitions or are analytical artefacts is uncertain (Tsukamoto and Arai, 2001; Kotake et al., 2003; Jessop et al., 2008) but Panfili et al. (2012) suggest that they represent true habitat transitions.

Different otolith element and statistical analytical methods may differ in their results. Such differences may be of no consequence or may be of biological and/or statistical significance, although statistical significance does not assure biological importance (Martínez-Abraín, 2008). The otolith Sr:Ca critical value can be expected to vary among studies due to the incorporation of ambient water variability in $\mathrm{Sr}$ :Ca level resulting from geological and environmental conditions (Kraus and Secor, 2004; Brown and Severin, 2009; Walther and Limburg, 2012). The degree to which inter-habitat movements may be determined depends on the magnitude of the difference between ambient fresh and saline water $\mathrm{Sr}$ :Ca values. The method of determining the HDCV may also have an effect. For example, some studies simply apply HDCVs taken from other studies that are presumed to be appropriate based on the observed otolith $\mathrm{Sr}$ :Ca transect values for putative habitat groups in each study (Kotake et al., 2003, 2004, 2005; Cairns et al., 2004; Jessop et al., 2009; Lin et al., 2012). Other studies estimate a freshwater/estuarine Sr:Ca HDCV in various arbitrary ways: as the upper limit of the range of mean otolith $\mathrm{Sr}$ :Ca values for putative freshwater residents (Tzeng et al., 1997, 2002; Tsukamoto and Arai, 2001; Jessop et al., 2002), or as the freshwater mean plus 2 or 3SD (Shiao et al., 2006; Tabouret et al., 2010; Jessop et al., 2011; Lin et al., 2011). Habitat separation has also been based on Gaussian probability distributions for each habitat group (Daverat and Tomás, 2006), by a Bayesian method (Fablet et al., 2007), by zoning algorithms (Hedger et al., 2008), and by linear discriminant analysis (LDA) (Panfili et al., 2012). The quantitative method of zoning algorithms produced results that were not significantly different from those produced by a qualitative approach to life-history classification (Hedger et al., 2008).

A variety of smoothers has also been applied to otolith $\mathrm{Sr}: \mathrm{Ca}$ transect data, such as 2-point (Thibault et al., 2007), 5-point (Lamson et al., 2006), 9-point (Cairns et al., 2004), and LOWESS (locally weighted robust regression) (Jessop et al., 2008).

Discriminant function analysis, either linear or quadratic, has often been applied to otolith element:Ca data to classify the habitat origins and residences of individual fish based on the optimal combination of multiple element:Ca signatures (Gillanders and Kingsford, 2000; Brown, 2006; Ziegler and Whitledge, 2010; Bradbury and DiBacco, 2011). It has rarely been applied to the simple single factor (habitat residence), two-group (freshwater, estuarine/marine) case with only a single predictor variable ( $\mathrm{Sr}: \mathrm{Ca}$ ) (Panfili et al., 2012).

The objectives of this study are to: (a) evaluate the effect of otolith Sr:Ca value sample size on the estimation of a habitat discrimination critical value (HDCV); (b) show that for the single factor, two-group case, the categorization of individual $\mathrm{Sr}: \mathrm{Ca}$ values as either freshwater or estuarine/marine in nature by linear discriminant analysis (LDA) can be replicated by calculations done by spreadsheet; (c) demonstrate empirical relations based on published studies between the freshwater resident mean $+c S D$, where $c$ is a coefficient, and the freshwater-to-estuarine habitat transition critical value (HDCV) for anguillid eel otolith $\mathrm{Sr}$ :Ca values estimated by LDA; (d) evaluate the effect of HDCV selection on the estimation of the proportion of continental residence in freshwater (\%fwr) for individual eels and thus also of estuarine/ marine residence; and (e) evaluate the relation between varying estimates of \%fwr and estimates of annual eel growth rate because growth rate varies with salinity (Jessop et al., 2004, 2008; Daverat and Tomás, 2006) and is of fundamental importance in many fishery studies.

\section{Materials and methods}

\subsection{Study sites and sampling}

Muddy Hole ( $\mathrm{MH})$, a cove at the mouth of Flat Bay Brook $\left(48^{\circ} 24^{\prime}\right.$ $\left.27^{\prime \prime} \mathrm{N},-58^{\circ} 34^{\prime} 41^{\prime \prime} \mathrm{W}\right)$ and Castors River (CR) $\left(50^{\circ} 55^{\prime} 15^{\prime \prime} \mathrm{N},-56^{\circ}\right.$ $57^{\prime} 07^{\prime \prime} \mathrm{W}$ ) are on the western coast of Newfoundland. Muddy Hole is a tidal, estuarine cove of about 17 ha in area at the mouth of Flat Bay Brook that may become entirely freshwater at high discharges from Flat Bay Brook. American eels were collected from commercial fyke net fisheries at Muddy Hole ( $n=57$, of which 53 had data sufficient for this study) and at Castors River ( $n=59$, of which 2 eels were male and/or had no age data and were excluded from the growth rate analysis) at a site about $11 \mathrm{~km}$ upstream from the river mouth. The total $n=112$ except that $n=110$ for the growth rate analysis. Total lengths (to $1.0 \mathrm{~mm}$ ) and total body weights (to $0.1 \mathrm{~g}$ ) were measured fresh. Most eels from the Castors River were silver phase while most from Muddy Hole were yellow phase. Jessop et al. (2009) provides additional details of the study sites, sampling, processing, aging, and biological characteristics of the eels. 


\subsection{Otolith microchemistry analysis}

Sagittal otoliths were prepared for electron probe microanalysis and the strontium ( $\mathrm{Sr}$ ) and calcium (Ca) concentrations were measured along a transect of the sagittal plane of the otolith from the primordium to the otolith edge with electron beam spot sizes of about $5 \mu \mathrm{m}$ spaced at intervals of approximately $10 \mu \mathrm{m}$ as described by Tzeng et al. (1997) and Jessop et al. (2002). The environmental history of each eel was interpreted by examining the temporal pattern of Sr:Ca ratio values along the otolith transect, with the assumption that the temporal pattern reflects habitat salinity due to the positive relation between otolith $\mathrm{Sr}$ :Ca value and ambient salinity (Tzeng, 1996; Kawakami et al., 1998; Secor and Rooker, 2000). All otolith Sr:Ca values are expressed as wt\% ratios (equivalent to $\mathrm{mg} \mathrm{g}^{-1}$ ) and presented as value $\times 10^{-3}$, unless otherwise noted. The percentage (proportion) of freshwater residence was estimated as the percentage of Sr:Ca ratio values between the elver check and the otolith edge less than or equal to a critical value (Jessop et al., 2004, 2006, 2008).

\subsection{Data analysis}

\subsubsection{Linear discriminant analysis}

Linear discriminant analysis (LDA) was performed by the lda function of the MASS package of the statistical program $R$ ( $R$ Development Core Team, 2011). The discrimination process was conducted on a primary training set of otolith Sr:Ca data from 15 eels from each of a freshwater site (Castors River) and an estuarine site (Muddy Hole) that had been evaluated as either of totally freshwater or estuarine origin based on their transect profiles from elver check to edge (consistently low or high Sr:Ca values). Post hoc analysis indicated a mean \%fwr of 97.0 (range $=93.5-100$ ) for the freshwater group and 2.6 (range $=0-5.6$ ) for the estuarine group. A jackknife leave-one-out cross-validation method was used to estimate the accuracy of the LDA classification of Sr:Ca values to salinity group. The discriminant function was then applied to the total data set (112 eels) to classify individual Sr:Ca values for each eel from elver check to edge as of either freshwater or estuarine origin. Priors for the classification process were set at 0.5 .

In the two-group case, LDA is equivalent to Fisher's discriminant analysis and is analogous to multiple regression (Venables and Ripley, 2002). Fisher's linear discriminant provides an explicit estimate of the threshold constant $c$ (or HDCV) as equal to the average of the group (freshwater, estuarine) mean Sr:Ca values

$\mathrm{HDCV}=\frac{\left(\bar{x}_{1}+\bar{x}_{2}\right)}{2}$

This assumes that: (a) population variances are equal, (b) a normal population distribution, (c) equal priors (equal distribution of the two groups in the population), and (d) equal misclassification costs (calling a case as group 1 when it is group 2 is as bad as the reverse).

The assumptions of normality of distribution and homogeneity of variances underlying parametric statistical analysis were checked for the distribution of otolith $\mathrm{Sr}$ :Ca values for each otolith Sr:Ca sample size group (SSG; see Section 2.3.2) from each site (CR, $\mathrm{MH}$ ) by quantile-quantile plots for normality and boxplots, Cleveland dotplots, and the $F_{\max }$ test for heterogeneity (Sokal and Rohlf, 1981; Zuur et al., 2007). For each otolith Sr:Ca SSG from each site $(\mathrm{CR}, \mathrm{MH})$, heterogeneity of variances for $\mathrm{Sr}$ :Ca data was minor (Fig. 1), with $F_{\max }$ test values all less than 2.5, indicating moderate, but acceptable, heterogeneity. There were no significant outliers. The Muddy Hole SSGs had acceptably normal Sr:Ca value distributions but the Castors River data were moderately to highly positively skewed due to the numbers of zero (below detection

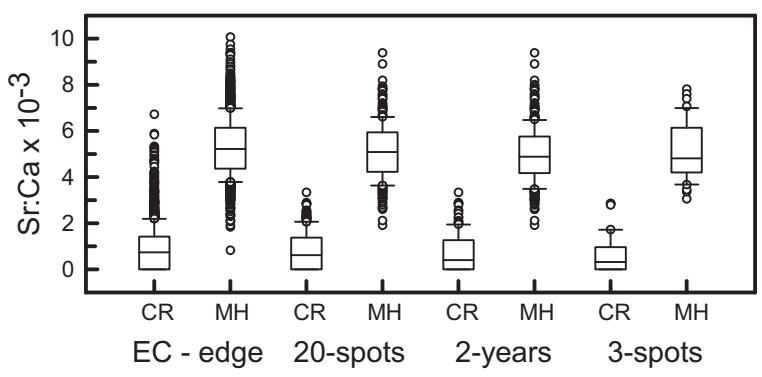

Fig. 1. Anguilla rostrata. Boxplots of otolith Sr:Ca values from between the elver check and edge, by sample size group, for American eels classified as freshwater resident from Castors River and estuarine resident from Muddy Hole, western Newfoundland. Group sample sizes ( $n$ ) are given in Table 1.

limits of $0.09 \times 10^{-3}$ ) Sr:Ca values from freshwater resident eels which are a consequence of the analytical method and low ambient water Sr:Ca level $\left(1.59 \times 10^{-3}\right.$, Jessop et al., 2011). No transformation of Sr:Ca values was judged to be required for the LDA analysis. Approximate normality is only required for hypothesis tests related to the LDA, none of which are made, and is unnecessary for LDA per se (Hair et al., 1998). Violations of normality are not a serious problem when caused by skewness rather than outliers (Zuur et al., 2007) and skewness on the lowest distribution tail (of the freshwater group) does not affect the degree of overlap between sample group distributions.

\subsubsection{Sample size groups}

The LDA classification process is influenced by the sample size of the otolith Sr:Ca values from each eel used in the training set ( $n=15$ eels from each site) for the discriminant process. Consequently, four sample sizes of $\mathrm{Sr}$ :Ca values along the otolith transect from elver check to edge for each eel that reasonably cover the available sample size range were used to create $\mathrm{Sr}$ :Ca value sample size groups (SSGs) based on the eels in the LDA training set. The SSGs were then used in the discriminant process and then evaluated for their effect on the Sr:Ca value classification results in terms of mean group Sr:Ca values and the number of values classified as freshwater: all Sr:Ca values from elver check to edge (EC-edge; used as the primary training set), last $20 \mathrm{Sr}$ :Ca values and last 3 $\mathrm{Sr}:$ Ca values from the edge, and the variable number of Sr:Ca values from the edge to the penultimate annulus (final 2 years of life; 2yrs). Otolith $\mathrm{Sr}$ :Ca values across a transect from core to edge are not independent but are serially correlated. For each site, the significance of any difference between mean otolith $\mathrm{Sr}$ :Ca values from the four sample size groups was determined by mixed effects linear model analysis of variance (ANOVA) using R package nlme, with fish as a random effect nested within site, SSG as a fixed effect nested within fish, and autocorrelation in Sr:Ca values adjusted for by a first order autocorrelation function (AR1). The ANOVA was followed by a Tukey multiple comparison test using $\mathrm{R}$ package multcomp. The otolith Sr:Ca data from CR were logarithm (base $10)(x+0.1)$ transformed because of the presence of zero values (12.2\%) (Berry, 1987) and the MH data logarithm (base 10) transformed. The effect magnitude of any significant difference for a contrast was estimated as

$$
r=\sqrt{\frac{F}{F+\mathrm{df}_{\text {denom }}}}
$$

where the $F$ is from the ANOVA and the $\mathrm{df}_{\text {denom }}$ is the denominator degrees of freedom (Rosenthal, 1993). A 95\% confidence interval 
(CI) for $r$ was calculated by standard procedures following the $z$ transformation of $r$ (Zar, 1984).

The otolith Sr:Ca values for the total sample $(n=112)$ were classified as freshwater or estuarine by applying the discriminant analysis function from each SSG to the classification process. The resultant counts of freshwater $\mathrm{Sr}$ :Ca cases for each eel in the total sample, for each SSG, were examined for compliance with the requirements of parametric statistics by the D'Agostino-Pearson $K^{2}$ statistic (D'Agostino et al., 1990) for normality and $F_{\max }$ test for homogeneity of variances. Simple logarithmic transformation (base 10) was sufficient for the Castors River count data but logarithm (base 10) $(x+0.5)$ transformation was best for the Muddy Hole data, which contained 6-8\% zeros (Berry, 1987).

Statistical significance of the difference between the counts of $\mathrm{Sr}:$ Ca values categorized by LDA as freshwater within each freshwater discriminant analysis SSG was determined, for each site, by paired sample $t$-test for the 6 possible pairs. No Bonferroni correction was made. The Hedges' $g$ effect size statistic and associated $95 \% \mathrm{CI}$ was used as a measure of the magnitude of the effect size of each difference, where

$g=t \quad{ }_{\text {paired }} \sqrt{\frac{2\left(1-r_{12}\right)}{n}}$

and $t_{\text {paired }}$ is the $t$ value from a paired $t$-test, $r_{12}$ is the correlation coefficient between the two groups and $n=n_{1}=n_{2}$ (Nakagawa and Cuthill, 2007). Effect size ( $g$ ) values of 0.2 are considered small, 0.5 are medium, and 0.8 are large (Cohen, 1988). Effect size can be conceptualized as the significance-test statistic/sample size (Tatsuoka, 1993).

\subsubsection{Relations between $H D C V$ and the mean $+c S D$ equation}

Estimates of the LDA HDCV for this study for the different SSGs and for 13 published studies (Table 1) were examined for their relation to the variables of the freshwater mean $+c S D$ relation between otolith Sr:Ca values for freshwater and estuarine/marine group temperate-zone anguillid eels.

\subsubsection{Estimation of percent freshwater residence (\%fwr)}

The \%fwr was estimated for each fish $(n=112)$ as the percentage of freshwater Sr:Ca values along the otolith transect from elver check to edge based on the LDA HDCV for each SSG. The $20 \mathrm{Sr}: \mathrm{Ca}$ value SSG was chosen as the reference value for comparing estimates of \%fwr with those from each of the other SSGs. Next, the \% fwr values were transformed by the arcsine of the square root of $p$ estimates before calculating the significance of the difference in \% fwr between SSGs by the paired sample $t$-test ( 6 combinations) and determining the magnitude of the effect size by Hedges' $g$, as described above.

Estimates of \%fwr values were also made using a critical value based on the freshwater training set ( $n=15$ eels), elver check to otolith edge grand mean otolith $\mathrm{Sr}: \mathrm{Ca}$ value $\left(0.922 \times 10^{-3}\right.$, $n=1958)$ plus 2 or $3 \mathrm{SD}\left(0.953 \times 10^{-3}\right)$ for comparison with the LDA HDCV derived values (Table 1 ). The effect for individual eels $(n=112)$ on estimated \%fwr relative to the associated mean otolith $\mathrm{Sr}:$ Ca value of "incorrectly" chosen HDCVs was evaluated by comparison of the results of using HDCVs of $2.0,3.0$, and $4.0 \times 10^{-3}$ that bracket the range of observed HDCVs from the LDA method applied to this and 13 published studies. The \%fwr values were transformed by the arcsine of the square root of $p$ estimates before calculating the significance of the difference in \%fwr between the three HDCV groups by the paired sample $t$-test and determining the magnitude of the effect size by Hedges' $g$.

Anguillid eel lengths and annual growth rates increase with increasing habitat salinity and water temperature (Melià et al., 2006; review by Jessop et al., 2008). The effect of HDCV choice on the categorization of Sr:Ca values as freshwater or estuarine on the relation between \%fwr and growth rate $(n=110)$ was evaluated by analysis of covariance (ANCOVA). Annual mean growth rate was calculated by $[(\mathrm{TL}-\mathrm{EL}) /$ age $] \times 100$, where $\mathrm{EL}=$ mean elver length

Table 1

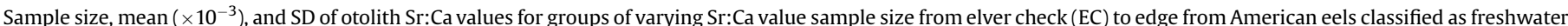

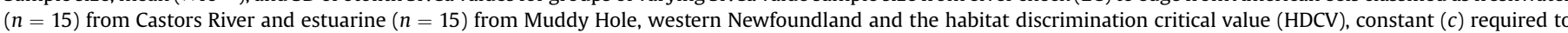

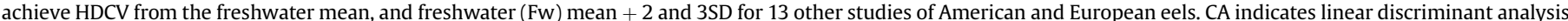
(LDA) classification accuracy. Means without a letter in common differ significantly $(\mathrm{p}<0.05)$ from each other.

\begin{tabular}{|c|c|c|c|c|c|c|c|c|c|c|c|c|}
\hline \multicolumn{3}{|c|}{ Freshwater } & \multicolumn{3}{|c|}{ Estuarine } & \multirow[t]{2}{*}{ HDCV } & \multirow[t]{2}{*}{ c } & \multirow[t]{2}{*}{ Fw mean $+2 \mathrm{SD}$} & \multirow[t]{2}{*}{ Fw mean $+3 S D$} & \multirow[t]{2}{*}{ CA (\%) } & \multirow[t]{2}{*}{ Mean difference } & \multirow[t]{2}{*}{ Group/Reference } \\
\hline$n$ & Mean & SD & $n$ & Mean & SD & & & & & & & \\
\hline 45 & $0.62^{\mathrm{a}}$ & 0.781 & 45 & $5.14^{\mathrm{c}, \mathrm{d}}$ & 1.23 & 2.88 & 2.89 & 2.19 & 2.97 & 100 & 4.52 & 3 value \\
\hline 153 & $0.74^{\mathrm{a}}$ & 0.82 & 396 & $4.99^{\mathrm{d}}$ & 1.19 & 2.86 & 2.59 & 2.38 & 3.20 & 98.7 & 4.25 & 2 years \\
\hline 300 & $0.80^{\mathrm{a}}$ & 0.81 & 300 & $5.12^{\mathrm{c}, \mathrm{d}}$ & 1.23 & 2.96 & 2.69 & 2.41 & 3.21 & 98.3 & 4.32 & 20 value \\
\hline \multirow[t]{16}{*}{1958} & $0.92^{\mathrm{a}}$ & 0.95 & 1423 & $5.30^{c}$ & 1.27 & 3.11 & 2.30 & 2.83 & 3.78 & 97.1 & 4.38 & EC to edge \\
\hline & & & & & Mean & 2.95 & 2.62 & & & & & \\
\hline & 0.34 & 0.58 & & 4.75 & 0.21 & 2.54 & 4.39 & 1.50 & 2.08 & & 4.41 & Tzeng et al., 2005 \\
\hline & 0.57 & 0.61 & & 5.24 & 1.28 & 2.91 & 3.84 & 1.79 & 2.40 & & 4.67 & Lamson et al., 2006 \\
\hline & 0.64 & 0.66 & & 4.76 & 1.22 & 2.70 & 3.11 & 1.96 & 2.62 & & 4.12 & Cairns et al., 2004 \\
\hline & 0.71 & 0.89 & & 5.39 & 1.09 & 3.05 & 2.64 & 2.48 & 3.37 & & 4.68 & Tzeng et al., 2000 \\
\hline & 0.72 & 0.76 & & 4.84 & 1.61 & 2.78 & 2.71 & 2.24 & 3.00 & & 4.12 & Shiao et al., 2006,a \\
\hline & 0.80 & 0.81 & & 5.12 & 1.23 & 2.96 & 2.69 & 2.41 & 3.21 & & 4.32 & 20 value \\
\hline & 1.32 & 0.30 & & 4.63 & 1.21 & 2.98 & 5.52 & 1.92 & 2.22 & & 3.31 & Le et al., 2010 .b \\
\hline & 1.64 & 0.92 & & 6.15 & 1.22 & 3.90 & 2.48 & 3.48 & 4.39 & & 4.51 & Jessop et al., 2002,c \\
\hline & 1.70 & 0.97 & & 4.63 & 1.36 & 3.16 & 1.51 & 3.63 & 4.60 & & 2.93 & Thibault et al., 2007,d \\
\hline & 1.79 & 0.46 & & 6.46 & 1.44 & 4.13 & 4.09 & 2.71 & 3.17 & & 4.67 & Tabouret et al., 2010 \\
\hline & 2.10 & 0.35 & & 5.08 & 0.74 & 3.59 & 4.25 & 2.80 & 3.15 & & 2.98 & Morrison et al., 2003 \\
\hline & 2.11 & 0.81 & & 5.28 & 1.10 & 3.70 & 1.95 & 3.74 & 4.55 & & 3.17 & Tzeng et al., 2002,e \\
\hline & 2.7 & 0.47 & & 5.22 & 1.39 & 3.96 & 2.63 & 3.64 & 4.11 & & 2.52 & Panfili et al., 2012 \\
\hline & 3.13 & 1.12 & & 5.66 & 0.97 & 4.40 & 1.13 & 5.37 & 6.49 & & 2.53 & Lin et al., 2007,f \\
\hline
\end{tabular}

a Otolith Sr:Ca ratios $<2.24 \times 10^{-3}$ were classified as freshwater, $>3.23 \times 10^{-3}$ as estuarine/marine.

b Otolith Sr:Ca mean ratios $<2.5 \times 10^{-3}$ were classified as freshwater, $>2.5 \times 10^{-3}$ and $<6.0 \times 10^{-3}$ as estuarine.

c Otolith Sr:Ca ratios $<4.0 \times 10^{-3}$ were classified as freshwater, $>5.0 \times 10^{-3}$ as estuarine/marine.

d Otolith $\mathrm{Sr}$ :Ca ratios between $3.5 \times 10^{-3}$ and $4.0 \times 10^{-3}$ demarcated fresh from brackish water habitats.

e Otolith $\mathrm{Sr}$ :Ca ratios $<4.0 \times 10^{-3}$ were classified as freshwater.

f Estuarine salinity 15. 
$(\mathrm{mm})$ at Newfoundland latitudes estimated as $63.7 \mathrm{~mm}$ from Dutil et al. (1989). Given that fish growth rate commonly declines nonlinearly with age and the age structures of the eels differed between sites (habitats; Muddy Hole mean age $=6.2$ years, Castors River mean age $=19.5$ years), the growth rates were logarithmically (base 10) transformed while the \%fwr values were transformed by the arcsine of the square root of $p$ estimates. An overall effect size (measure of association) for the ANCOVA was the correlation coefficient $\left(r_{\mathrm{adj}}\right)$ adjusted for the number of independent variables (Nakagawa and Cuthill, 2007). The effect size statistic $d$ for contrasts among adjusted (standardized) mean growth rates was estimated as

$d=\frac{Y_{1}-Y_{2}}{S_{\text {pooled }}}$

where $Y_{1}$ and $Y_{2}$ are adjusted means and

$s_{\text {pooled }}=\sqrt{\frac{\mathrm{MS}_{\text {error }}}{1-r^{2}} \cdot \frac{\mathrm{df}_{\text {error }}-1}{\mathrm{df}_{\text {error }}-2}}$

where $\mathrm{MS}_{\text {error }}$ is the mean square error and $\mathrm{df}_{\text {error }}$ is the error degrees of freedom from the ANCOVA (Lipsey and Wilson, 2001). For the effect size statistic $d$, a small effect $=0.2$, a medium effect $=0.5$, and a large effect $=0.8$ (Cohen, 1988). All correlations between variables in Table 1 and their statistical significance were adjusted for small sample size as described in Jessop (2010). Statistical significance was accepted at $\alpha \leq 0.05$.

\section{Results}

\subsection{Sample size groups}

The mean otolith Sr:Ca values for the four SSGs differed significantly for the Castors River data (freshwater group, eel $n=15)(F=3.86, \mathrm{df}=3,2438, p=0.009)$ and for the Muddy Hole data (estuarine group, eel $n=15)(F=3.83$, df $=3,2146$, $p=0.01$ ). The overall effect size measure $r$ was $\leq 0.05$ and of trivial magnitude for both ANOVAs. Multiple comparison tests indicated no significantly different paired contrasts among Sr:Ca SSGs for the freshwater group (all $p>0.088$ ). For the estuarine group, a significant difference occurred for the EC to edge versus 2 years SSG contrast $(p=0.009)$, for which the effect size $d$ was 0.07 , with all other contrasts having $p>0.19$ (Table 1 ). The autocorrelation within the Sr:Ca data was higher for Muddy Hole $(r=0.246)$ than for Castors River $(r=0.159)$. The Sr:Ca sample sizes for individual eels $(n=15)$ varied for the 2 years group from 5 to $31 \mathrm{Sr}$ :Ca values (mean $=10.2$ ) for the older fish from the freshwater Castors River (mean age $=21.1$ years, range $=13-32$ years) and from 16 to 47 (mean $=26.4$ ) for the younger eels (mean age $=5.7$ years, range $=3-9$ years) from the estuarine Muddy Hole. For the elver check (EC) to edge SSG, the number of otolith Sr:Ca values ranged from 101 to 163 for individual Castors River eels and from 71 to 119 for Muddy Hole eels. The variability in otolith Sr:Ca values clearly decreased with decreasing otolith Sr:Ca sample size for each site, as did the mean (Figs. 1 and 2).

Differences in the otolith $\mathrm{Sr}$ :Ca sample size used to estimate a critical value produced significant differences in the number of Sr:Ca values classified as freshwater. All but one of the paired sample $t$-tests of the differences between SSGs ( 6 comparisons) in the number of $\mathrm{Sr}: \mathrm{Ca}$ values classified as freshwater for both Muddy Hole and Castors River were highly significant (MH: $t$ values from 2.02 to 8.52 , $\mathrm{df}=2,53$, one $p=0.048$, all others $\leq 0.002$; CR: $t$-values from 3.13 to 7.24 , $\mathrm{df}=2,58$, all $p \leq 0.002)$. The comparable Hedges' $g$ values ranged from 0.005 (95\% CI 0.00004 to 0.00922$)$ to 0.14 ( $95 \%$ CI $0.098-0.183$ ) for Muddy Hole and from 0.009 (95\% CI $0.006-0.013$ ) to 0.059 (95\% CI $0.039-$ 0.078 ) for Castors River.

\subsection{Linear discriminant analysis}

The LDA Sr:Ca critical values varied among SSGs, were largest for the EC-edge group and generally increased with increasing sample size (Table 1). The LDA output from $R$ does not provide an estimate of the linear threshold constant or classification boundary $c$ (equivalent to the HDCV) although it employs it in internal calculation. Fisher's linear discriminant provides an explicit estimate of the threshold constant $c$ as equal to the mean of the group (freshwater, estuarine) mean Sr:Ca values. For example, the ECedge freshwater group $\mathrm{Sr}: \mathrm{Ca}$ value mean of $0.922 \times 10^{-3}$ and $5.303 \times 10^{-3}$ for the estuarine group produced an LDA HDCV of $3.11 \times 10^{-3}$. The classification accuracy of the LDA increased with decreasing sample size from $97.1 \%$ to $100 \%$. Classification accuracy differed trivially for the EC-edge group when estimated with equal priors (97.13\%) and when estimated with priors equal to group $n$ (97.07\%).
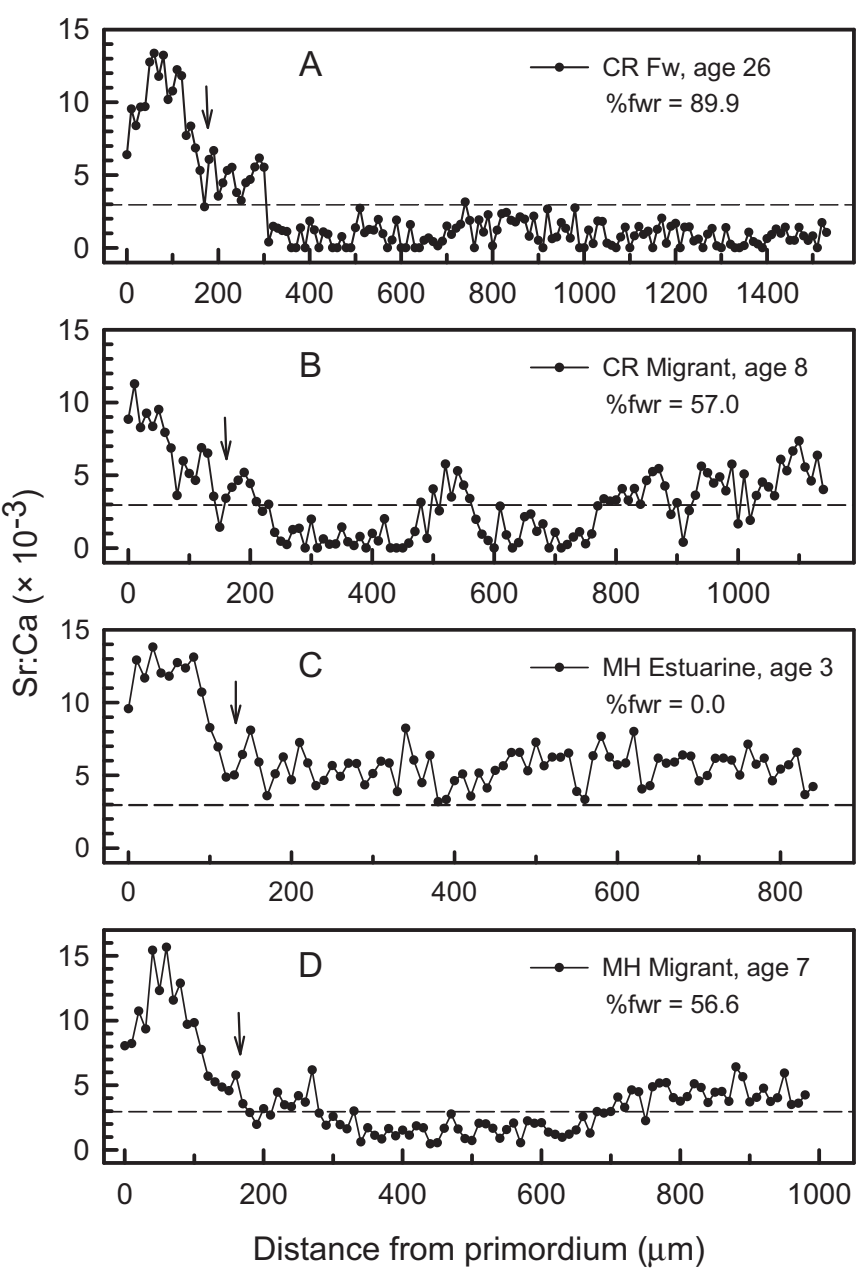

Fig. 2. Anguilla rostrata. Otolith $\mathrm{Sr}: \mathrm{Ca}$ values along a transect from core to edge for otoliths of selected individual American eels from Castors River (CR) and Muddy Hole $(\mathrm{MH})$, western Newfoundland representing notable life-history patterns. The elver check position is indicated by a vertical arrow, Fw indicates a freshwater residence history, and \%fwr is the percent of freshwater residence. The dashed line represents the habitat discrimination critical value $\left(\mathrm{HDCV}, 3.11 \times 10^{-3}\right)$. 


\subsection{Relations between freshwater and estuarine otolith $\mathrm{Sr}: \mathrm{Ca}$}

Otolith $\mathrm{Sr}: \mathrm{Ca}$ habitat group mean values for estuarine resident anguillid eels from 14 studies (Table 1) increased slightly, but not significantly ( $n=14, r=0.38,95 \% \mathrm{CI}-0.19$ to $0.76, p=0.17$ ), with increasing freshwater group otolith Sr:Ca mean values. Freshwater group mean otolith $\mathrm{Sr}$ :Ca values were more variable (coefficient of variation $=0.596$ ) than were estuarine group mean $\mathrm{Sr}$ :Ca values (0.105). However, the difference between estuarine and freshwater group mean otolith $\mathrm{Sr}$ :Ca values decreased significantly with increasing freshwater group mean otolith $\mathrm{Sr}$ :Ca value $(n=14$, $r=0.80,95 \%$ CI $0.45-0.93, p=0.00054)$.

\subsection{Relations between the HDCV and the mean $+c S D$}

The HDCV is related to the freshwater group mean otolith $\mathrm{Sr}: \mathrm{Ca}$ value and its SD via the coefficient $c$, where the $\mathrm{HDCV}=$ mean $+(c \times \mathrm{SD})$. This relation is a consequence of the nature of Fisher's linear discriminant for the two-group case and the high variability in freshwater mean otolith $\mathrm{Sr}$ :Ca values relative to estuarine/marine Sr:Ca values. Otolith mean $\mathrm{Sr}: \mathrm{Ca}$ values for freshwater resident eels from the 14 studies examined ranged from 0.34 to $3.13\left(\times 10^{-3}\right.$ implied $)$ and for estuarine residents from 4.63 to 6.46 , producing LDA HDCVs ranging from 2.54 to 4.40 (Table 1 ). The HDCV increased significantly with both freshwater $(n=14$, $r=0.90,95 \%$ CI 0.73-0.97, $p<0.00001$; Fig. 3A) and estuarine $(n=14, r=0.74,95 \%$ CI 0.35-0.91, $p=0.0019$ ) group mean Sr:Ca values. The relation between the HDCV and the difference between freshwater and estuarine group mean $\mathrm{Sr}$ :Ca values was parabolic, with high HDCVs at both low and high mean differences and the HDCV low at a mean difference of 3.5-4.0 $(n=14, r=0.73,95 \% \mathrm{CI}$ $0.29-0.90, p=0.0033$ ). Thus, as the freshwater group mean increased toward the estuarine mean or the estuarine mean increased, the HDCV increased. The value of $c$ declined with increasing freshwater group SD $(n=14, r=-0.89,95 \% \mathrm{CI}-0.66$
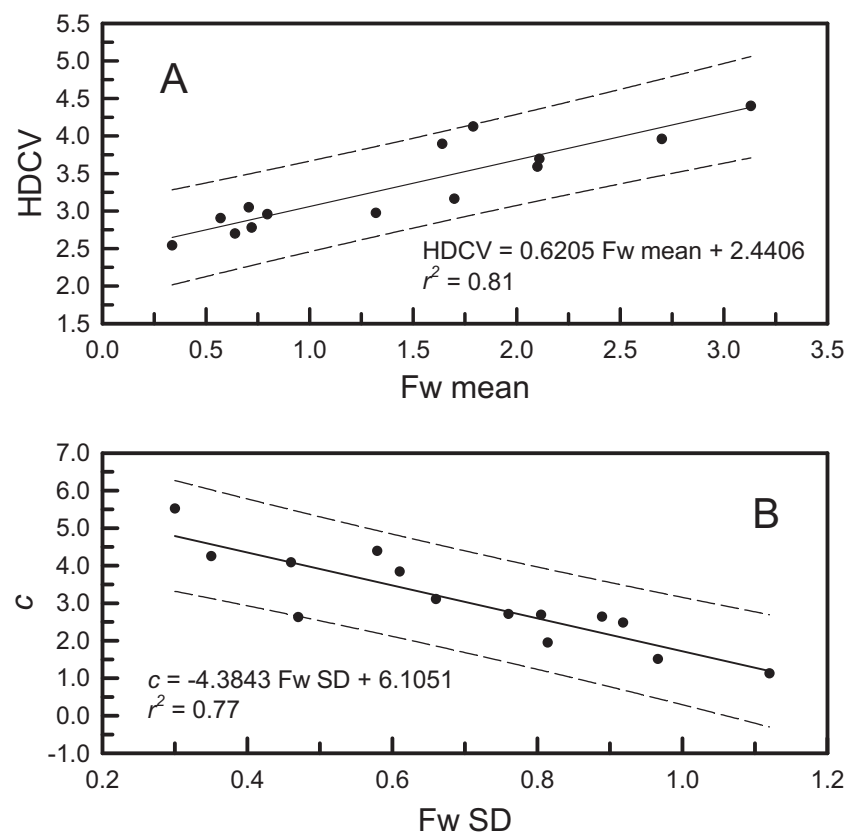

Fig. 3. Anguilla rostrata. A. Habitat discrimination critical value (HDCV) in relation to the freshwater mean otolith Sr:Ca values from the elver check to edge; B. Constant $c$ in relation to the SD of freshwater otolith $\mathrm{Sr}$ :Ca values based on the relation $\mathrm{HDCV}=\mathrm{Fw}$ mean $+c S D$ for 13 published studies of American, European and Lapanese eels and the present study of American eels from western Newfoundlar to $-0.96, p=0.00002$; Fig. $3 \mathrm{~B}$ ) but the increase in $c$ with an increasing difference between the freshwater and estuarine group means was non-significant ( $n=14, r=0.33,95 \% \mathrm{CI}-0.25$ to 0.73 , $p=0.25$ ). The median of the $c$ values from this (20 spot value) and 13 other studies of American, European, and Japanese eels was 2.7 (range 1.13-5.52).

The LDA HDCV was intermediate between the freshwater group mean +2 SD and freshwater mean +3 SD in 5 of 14 cases, exceeded the freshwater group mean +3 SD in 6 cases by $0.08-0.96\left(\times 10^{-3}\right)$, and was less than the freshwater mean +2 SD in 3 cases by $0.04-$ 0.97. A robust approach for estimating a HDCV when only the freshwater group otolith $\mathrm{Sr}: \mathrm{Ca}$ mean and SD data are available utilizes the observed relations between the freshwater mean $+c S D$ and the LDA HDCV between freshwater and estuarine group otolith $\mathrm{Sr}$ :Ca values. The highly significant relation between the freshwater otolith group Sr:Ca mean and the LDA HDCV can be used to first estimate a HDCV from the linear regression equation $\mathrm{HDCV}=(0.6205 \times \mathrm{Fw}$ mean $)+2.4406$, where the group mean $\mathrm{Sr}:$ Ca values and HDCV are represented as, for example, 1.2 rather than $1.2 \times 10^{-3}$ (Fig. 3A). For example, given the Tzeng et al. (2005) freshwater otolith $\mathrm{Sr}$ :Ca group mean of 0.58 , the estimated HDCV is 2.65 which differs by -0.11 from the LDA HDCV. Applied to all of the cases, this process produced estimated HDCVs that were within \pm 0.5 of the LDA HDCV in 13 of 14 cases (median difference $=-0.09$, range $=-0.34$ to 0.56 ). The outlier case (HDCV difference $>0.50$ ), with a HDCV difference of 0.56 (Tabouret et al., 2010), had a high freshwater group mean $\mathrm{Sr}: \mathrm{Ca}(\geq 1.3)$ and low SD $(\leq 0.6)$. If each case is then adjusted by estimating a new $c$ from the linear equation $c=(-4.3843 \times$ Fw SD) +6.1051 (Fig. 3B), then estimating a new HDCV from the equation HDCV $=\mathrm{FW}$ mean $+c S D$, the estimated HDCV are within \pm 0.5 of the LDA HDCV in 13 of 14 cases (median difference $=0.08$, range $=-0.67$ to 0.42 ), including the Tabouret et al. (2010) data. The new outlier (Panfili et al., 2012) differed by -0.67 from the LDA HDCV and also had a high $\mathrm{Sr}$ :Ca group mean and low SD. Perhaps coincidentally, both outlier cases were based on estimates of freshwater group mean and SD on single edge Sr:Ca values from individual fish, a source of bias demonstrated in this study. Averaging the HDCV estimates from both equation processes produced HDCV estimates from freshwater group mean and SD data that were all within \pm 0.5 of the relevant LDA HDCV for all cases and $57 \%$ were within \pm 0.2 . The Hedges' $g$ value for the difference between HDCVs estimated by LDA and the mean $+c S D$ methods was 0.11 , a small effect size.

\subsection{Estimation of \%fwr}

The 20-value SSG LDA HDCV of $2.96\left(\times 10^{-3}\right)$ effectively distinguished totally freshwater from totally estuarine residents and was used a basis for estimating the \%fwr for individual fish (Fig. 2). Panel A of Fig. 2 represents an essentially freshwater life history for an eel of age 26 ; the \%fwr estimate of $89.9 \%$ is less than $100 \%$ because of the inclusion of a period of estuarine residence during the first year of continental arrival (after the elver check) before entering freshwater. Fully estuarine residence (\%fwr $=0)$ is shown in panel C. Inter-habitat migrant history is indicated by intermediate \%fwr values (panels B and D).

The mean SSG differences in the \%fwr values estimated for each eel based on the classification results derived from the LDA HDCVs for the 3 comparisons between the 20-value SSG and the remaining SSGs ranged from $0.24 \%$ fwr to $1.73 \%$ fwr. All of these differences were highly statistically significant ( $t$-values ranged from 6.81 to 11.47, $\mathrm{df}=2,58$, all $p<0.0001$ ). The corresponding Hedges' $g$ values ranged from 0.03 to 0.09 , representing very small effect sizes. For the Muddy Hole eels, the mean differences in \%fwr values ranged from $0.40 \%$ fwr to $1.95 \%$ fwr, and were highly statistically significant 
( $t$-values ranged from 3.95 to $9.63, \mathrm{df}=2,53$, all $p<0.0002$ ). The corresponding Hedges' $g$ values ranged from 0.03 to 0.17 . For the Castors River eels, values of \%fwr for individual eels ranged from $0 \%$ fwr to $5.96 \%$ fwr and for Muddy Hole eels from $0 \%$ fwr to $7.09 \%$ fwr.

The difference in \%fwr values for individual eels estimated at various HDCV levels increased with the difference in HDCV level and were highly statistically significant ( $t$-values ranged from 15.7 to 18.5 for differences of $0.5 \mathrm{HDCV}$ unit $\left(\times 10^{-3}\right.$ implied) to 21.4 for differences of one HDCV unit to 29.2 for a difference of $2 \mathrm{HDCV}$ units (HDCV 2.0-4.0), all $p$-values $<0.00001$ ). Hedges' $g$ ranged from 0.17 (95\% CI $0.14-0.20)$ to 0.21 (95\% CI 0.18-0.25) for a difference of 0.5 HDCV unit to about 0.37 (95\% CI $0.34-0.41$ ) for differences of $1 \mathrm{HDCV}$ unit to 0.73 (95\% CI $0.68-0.78)$ for a difference of 2 HDCV units.

For a given mean EC-edge otolith $\mathrm{Sr}$ :Ca for an individual eel, the estimate of \%fwr varied widely with the HDCV such that a higher HDCV produced a higher \%fwr and vice versa except at the tails where \%fwr values converge to 0 or $100 \%$ (Fig. 4). For example, at a mean Sr:Ca value of 4.0, the \%fwr for a HDCV of 2.0 was about $10 \%$ and $45 \%$ for a HDCV of 4.0 while at an $\mathrm{Sr}$ :Ca value of 2.0 , the \%fwr was about $60 \%$ for a HDCV of 2.0 and $84 \%$ for a HDCV of 4.0 . At \%fwr values greater than $90 \%$, the range of individual eel mean otolith $\mathrm{Sr}:$ Ca values converged for all HDCV values.

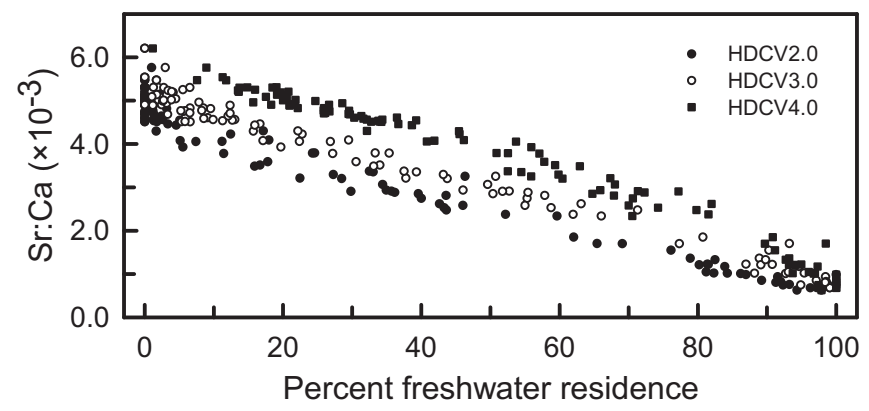

Fig. 4. Anguilla rostrata. Percent freshwater residence (\%fwr) in relation to mean otolith Sr:Ca values from the elver check to edge for a range of freshwater to saline water habitat discrimination critical values (HDCV) for American eels from the Castors River and Muddy Hole, western Newfoundland.

\subsection{Relation between $H D C V$, \%fwr, and growth rate}

The choice of critical value strongly affected the relationship between annual eel growth rate and the proportion of habitat residence in freshwater, with higher growth rates occurring for a given \%fwr with increasing HDCV (ANCOVA $F=29.2, \mathrm{df}=2,326$, $p<0.0001$ ) (Fig. 5). The overall effect size was $r_{\mathrm{adj}}=0.78$. The test for homogeneity of slopes was non-significant $(F=0.931, \mathrm{df}=2$, $324, p=0.395)$. Growth rate declined with increasing freshwater residence at all HDCVs, with the adjusted mean growth rate $(\log 10$ transformed) declining from 1.709 (95\% CI 1.685-1.733) at $\mathrm{HDCV}=4.0$ to $1.632(95 \% \mathrm{CI} 1.609-1.655)$ at $\mathrm{HDCV}=3.0$ to 1.574 (95\% CI 1.550-1.598) at HDCV $=2.0$. The effect size $d$ for the difference between adjusted mean growth rates was greatest for the HDCV4.0-HDCV2.0 comparison ( $d=0.0 .63$, 95\% CI 0.40-0.95), followed by that for HDCV4.0-HDCV3.0 $(d=0.39,95 \% \mathrm{CI}=0.120-$ $0.65)$ and HDCV3.0-HDCV2.0 $(d=0.29,95 \% \mathrm{CI}=0.02-0.55)$.

\section{Discussion}

\subsection{Sample size groups}

No standards exist for the estimation of habitat transition critical values (HDCV) for distinguishing residence in freshwater from

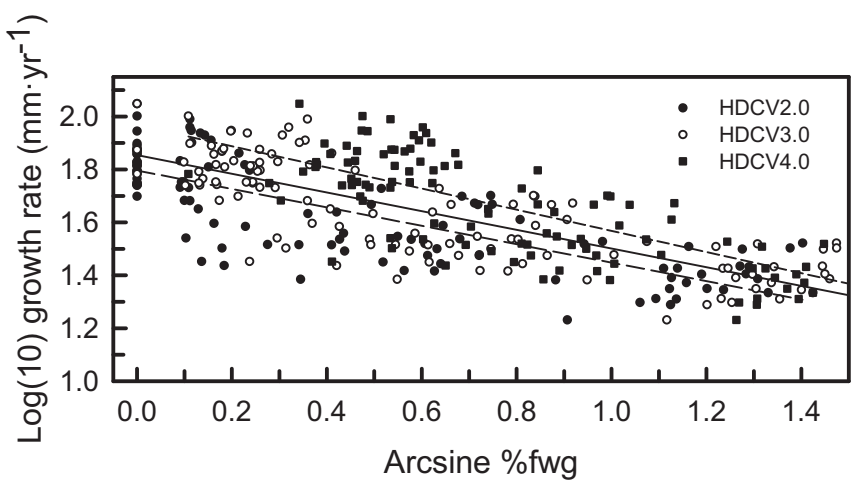

Fig. 5. Anguilla rostrata. Relation between mean annual growth rate and the proportion of freshwater residence (\%fwr) estimated for a range of otolith $\mathrm{Sr}$ :Ca habitat discrimination critical values (HDCV, $\times 10^{-3}$ ) for distinguishing between freshwater and estuarine residence for American eels from Castors River and Muddy Hole, western Newfoundland.

that in saline water for diadromous fishes such as the American eel. A priori, it is reasonable that a HDCV should be estimated independently for each study because of potential differences in ambient water $\mathrm{Sr}: \mathrm{Ca}$ levels among geographic areas. The first step in determining a HDCV is typically determining from the otolith transect profile those fish that can be presumptively classified as purely freshwater or saline water residents. Next may be the selection of the number of otolith Sr:Ca values used to estimate the sample statistics (usually mean and SD) of the general classification scheme for assigning fish to fresh or saline water residence. The entire transect from elver check to otolith edge is often selected (e.g., Daverat et al., 2006; Jessop et al., 2008). Very small otolith Sr:Ca sample sizes (e.g., $n=1-4$ ) per eel have been used in laboratory situations where recent growth is examined (Secor et al., 1995; Elsdon and Gillanders, 2005) and in natural studies (Jessop et al., 2011; Panfili et al., 2012) but small Sr:Ca sample sizes may underestimate the habitat group Sr:Ca mean and SD and introduce unnecessary bias into the use of the freshwater mean $+c S D$ method.

Despite overall statistical significance in mean otolith $\mathrm{Sr}: \mathrm{Ca}$ values among SSGs for both sites (mainly due to the influence of the large Sr:Ca sample sizes) and the occurrence of a significant difference for one paired contrast in the Muddy Hole (estuarine) group, the trivial magnitude of the effect size of the overall difference between Sr:Ca SSGs and for the one significantly different paired contrast suggests that the differences may not be practically or biologically meaningful and that in practice Sr:Ca sample sizes for individual otoliths can be selected as judged appropriate to a study. However, otoliths Sr:Ca sample size selection for HDCV estimation has effects on the subsequent application of a HDCV to estimating the \%fwr and habitat-specific growth rates, as discussed later, and larger sample sizes are preferred.

Adjustment of the number of tests made in multiple comparison procedures e.g., Bonferroni or sequential Bonferroni has been recommended against for ecological data (Moran, 2003; Nakagawa, 2004). However, a high degree of statistical significance is not necessarily evidence for a strong biological effect (Martínez-Abraín, 2008).

A sample size based on a biological criterion such as age (e.g., only fish of a given age used) may have some appeal but it results in widely varying sample sizes of $\mathrm{Sr}$ :Ca values for individual eels based on their specific age and growth rate. Equal sample sizes may be required for some statistical procedures (e.g., LDA discrimination process). Although the use of a moderate number of otolith $\mathrm{Sr}: \mathrm{Ca}$ values measured from the edge toward the core may be sufficient for 
estimating a HDCV, the entire transect from elver check to edge may be preferable if it is of a consistent habitat group because of the more complete reflection of the natural variability in ambient Sr:Ca values. The higher degree of autocorrelation in the Sr:Ca data for Muddy Hole (moderate effect size) than for Castors River (small effect size) may result from the larger variability in estuarine $\mathrm{Sr}$ :Ca values than for freshwater values.

The sample size per fish of Sr:Ca values used in the LDA discriminant function process greatly affected the number of $\mathrm{Sr}: \mathrm{Ca}$ values classified as freshwater during the classification process. The trivial effect size values of these comparisons suggest that these differences, despite high statistical significance, may not be important to the classification process and that comparable classification results may be achieved from widely varying Sr:Ca sample size groups during the discrimination process. The increasing classification accuracy with decreasing sample size may reflect the associated decreasing estimates of sample means, decreasing difference between sample means, and reduced variance which reduces the potential overlap in distributions. It also leads to a misguided conclusion that smaller SSGs may be best if high classification accuracy is desired. The decreasing mean and variance (SD) at smaller sample sizes for both freshwater and estuarine groups was due to failure to represent the full variability along the otolith EC-edge transect, including the exclusion of any estuarine values that may be present during the first year of continental residence. For the freshwater group, this was due to the frequent inclusion of high Sr:Ca values near the elver check resulting from formation of the elver check while in the estuary or delayed entrance to freshwater during the first 1-2 years of continental arrival (Jessop et al., 2007, 2008); for the estuarine group it resulted from the inclusion of a number of freshwater values. The classification accuracy of otolith Sr:Ca values by an LDA classification training set is determined by the "purity" of the freshwater and estuarine group data and sample size considerations as reflected in the degree of overlap of the training set otolith $\mathrm{Sr}$ :Ca values. Consequently, larger otolith $\mathrm{Sr}$ :Ca sample sizes are preferred for the discriminant function process because they better reflect the true variability in the data.

\subsection{Linear discriminant analysis, $H D C V$, and relation to mean $+c S D$}

Linear discriminant analysis can be applied to classify diadromous fish of unknown habitat origin when both freshwater and estuarine or marine reference groups are available. Given two habitat classification groups with variability only in the otolith $\mathrm{Sr}$ :Ca values distinguishing freshwater from estuarine residence, the critical value from the LDA discriminant process reduces to the grand average $\mathrm{Sr}$ :Ca value of the classification groups. Alternatively, the freshwater mean $+c \mathrm{SD}$ method has been used to distinguish freshwater from estuarine residence, with $c$ apparently arbitrarily set at values of 2 or 3 (Shiao et al., 2006; Tabouret et al., 2010; Jessop et al., 2011; Lin et al., 2011). The LDA HDCV was intermediate between that of HDCVs calculated from the freshwater mean + 2SD and mean +3 SD for only 5 (including this study) of 14 studies of American, European, and Japanese eels. In 9 of the studies, the mean + 2SD method produced HDCVs that were less than the LDA HDCV by $>0.5\left(\times 10^{-3}\right)$ and in 1 study the LDA HDCV was exceeded by $>0.5$. The freshwater mean +3 SD exceeded the LDA HDCV by $>0.5$ in 3 of 14 cases and was less than the LDA HDCV by $>0.5$ in 3 of 14 cases. Consequently, the arbitrary use of $c=2$ or 3 may produce moderately to substantially biased estimates of a HDCV and should be avoided. The proposed procedure based upon the strong empirical relations between the LDA HDCV and the freshwater mean $+c S D$ enables estimation of a HDCV that is usefully applied to putative inter-habitat migrants when only a freshwater habitat group is available. The method produces a HDCV biased by only a small effect size.

The applicability of the observed pattern in the mean $+c S D$ method for distinguishing between freshwater and estuarine/marine residence depends largely on the magnitude of the difference in mean otolith $\mathrm{Sr}$ :Ca values for each habitat group and their variance. It will not applied where the freshwater mean otolith $\mathrm{Sr}: \mathrm{Ca}$ values approach or exceed estuarine or marine otolith $\mathrm{Sr}$ :Ca values. Mean otolith $\mathrm{Sr}$ :Ca values were about $5.7 \times$ less variable (coefficient of variation) for estuarine residents than for freshwater residents. As the otolith mean $\mathrm{Sr}$ :Ca of freshwater residents increases, the difference between the freshwater mean otolith $\mathrm{Sr}: \mathrm{Ca}$ and the estuarine mean otolith $\mathrm{Sr}$ :Ca decreases due to the mixing effect of fresh and saline waters in the estuary (Walther and Limburg, 2012), the positive curvilinear relation between salinity and ambient $\mathrm{Sr}: \mathrm{Ca}$ (Macdonald and Crook, 2010), and because the variability of freshwater mean otolith Sr:Ca values is much higher (range $10 \times$ ) than for the more constant estuarine mean otolith $\mathrm{Sr}$ :Ca values (range $1.4 \times$ ), reflecting the large effect that watershed geology has on ambient Sr:Ca values (Walther and Limburg, 2012).

The range of ambient freshwater $\mathrm{Sr}$ :Ca values in coastal streams and rivers in the United States varies widely, from less than $1.0 \times 10^{-3}$ to over $40 \times 10^{-3}$ (Kraus and Secor, 2004; values converted from mmol mol${ }^{-1}$ ) and similar values occur globally (Brown and Severin, 2009; values converted from mmol mol${ }^{-1}$ ). About $60 \%$ of U.S. coastal streams and $79 \%$ of global streams evidently have ambient Sr:Ca values less than about 7.7-7.9 $\times 10^{-3}$, which may produce anguillid eel otolith $\mathrm{Sr}: \mathrm{Ca}$ values of less than about $3.2 \times 10^{-3}$ if a partition coefficient $\left(D_{\mathrm{Sr}}\right)$ of 0.4 is assumed for freshwater resident eels (Tabouret et al., 2010). All studies examined had mean eel otolith $\mathrm{Sr}$ :Ca values less than $3.2 \times 10^{-3}$. As freshwater otolith Sr:Ca values approach those for estuarine residence, the above pattern becomes less applicable. Higher freshwater $\mathrm{Sr}: \mathrm{Ca}$ values are expected to produce otolith $\mathrm{Sr}: \mathrm{Ca}$ values indistinguishable from those deposited in estuarine or marine environments. For example, freshwater otolith $\mathrm{Sr}$ :Ca values ranged up to $5.29 \times 10^{-3}$ for European eels from the Asi River, Turkey (Lin et al., 2011), values that would be considered estuarine in many studies. Ambient water Sr:Ca values, particularly for freshwater, are of great assistance in the interpretation of otolith Sr:Ca patterns and should be standard practice (Elsdon et al., 2008).

The freshwater mean $+c S D$ method would be difficult to use with a marine characteristic group in an analogous process to discriminate estuarine and marine groups because the generally curvilinear relation in the estuarine mixing plot of the Sr:Ca ratio results in ambient $\mathrm{Sr}$ :Ca ratios that approach marine values at low to moderate salinities, thereby limiting the ability to distinguish between residence in fully marine or mid-estuarine habitats (Walther and Limburg, 2012). Marine Sr:Ca values are typically about 18.6-18.8 × $10^{-3}$ (de Villiers, 1999). Tabouret et al. (2010) reported a $D_{S \mathrm{Sr}}$ of 0.33 for estuarine/marine-resident (salinity $>20$ ) yellow eels with otolith $\mathrm{Sr}$ :Ca values averaging $6.45 \times 10^{-3}$ (range $4.78-7.91 \times 10^{-3}$ ) which are comparable to other marine or sea eel mean otolith Sr:Ca values of 6.0-8.5 $\times 10^{-3}$ (Tsukamoto and Arai, 2001 ) and of $7.2 \times 10^{-3}$ (Le et al., 2010). Japanese eel elver $D_{\mathrm{Sr}}$ coefficients increased with increasing salinity from about 0.25 in freshwater to 0.43 at a salinity of 35 , with a $D_{\mathrm{Sr}}$ of about 0.36 at a salinity of 20 based on a laboratory study with the experimental waters derived from mixtures of natural freshwater and seawater (Lin et al., 2007). Phillis et al. (2011) found no evidence for significant $D_{\mathrm{Sr}}$ variation with salinity, although others have (de Vries et al., 2005; Zimmerman, 2005). Substantial variation may occur in $D_{\mathrm{Sr}}$ values within individual fish of a given species and among species (Brown and Severin, 2009). 
The discriminant and classification processes of LDA are usually done by a statistical program such as $\mathrm{R}$ but for single factor (Sr:Ca) data from two habitat groups these processes can be easily done by a spreadsheet program such as Excel. After calculation of a HDCV, either as the mean of freshwater and estuarine group means (LDA) or as the freshwater mean $+c \mathrm{SD}$, a simple classification decision rule (if an Sr:Ca value is less than the HDCV then classify as freshwater, otherwise classify as estuarine/marine) is applied to the transect of $\mathrm{Sr}: \mathrm{Ca}$ values from an individual fish. Estimates of $\mathrm{Sr}: \mathrm{Ca}$ value classification accuracy based on the training set in the LDA discriminant process with equal priors and Excel analyses were identical and equal to the sum of Sr:Ca values correctly classified to each group divided by the total sample size. The conclusion by Panfili et al. (2012) that the LDA procedure probably leads to different and more accurate conclusions about eel migratory behavior than does use of an Sr:Ca HDCV is incorrect - they lead to identical results. The classification accuracy is related to the degree of overlap of the two groups being classified and may be considered an effect size index when it "makes sense" for the response variable (Sr:Ca) to be considered a predictor (Huberty and Olejnik, 2006).

Priors for the LDA classification process were set at 0.5 rather than based on the relative $\mathrm{Sr}$ :Ca sample size $(n)$ of each eel habitat group because no information was available about the relative population sizes of each habitat group nor was a proportional sampling plan used for eel collection (Huberty and Olejnik, 2006). In any case, the classification accuracy was trivially different whether priors were set at 0.5 or as the relative $\mathrm{Sr}$ :Ca sample size of each habitat group.

\subsection{Estimation of \%fwr}

Estimating the \%fwr is useful for further categorizing habitat residents and inter-habitat migrants by the relative time spent in freshwater and saline habitats (Jessop et al., 2004, 2006; Elsdon and Gillanders, 2005) and for evaluating the effect of such residence on other factors such as growth rate (Jessop et al., 2004, 2009). The choice of HDCV for categorizing otolith Sr:Ca value as of freshwater or estuarine characteristic is important because it may greatly affect the estimate of \%fwr and result in incorrect categorization of habitat residence/migratory group (Jessop et al., 2011). Differences (bias) in HDCV of 0.5 units or more produced \%fwr values that were highly statistically significant but, more importantly, resulted in effect sizes that increased with the degree of difference in HDCV. Thus, a HDCV difference of 0.5 units had a small effect size while a 2 unit difference had a large effect size. A small effect size may represent a bias that is analytically tolerable and biologically of little importance (although the biological importance of small effect sizes needs further study) but larger effect sizes may be of serious concern. Consequently, the use of a mean +2 SD method for determining the HDCV of this data set generated a moderately large effect size underestimate of the \%fwr values for individual eels, assuming that the LDA method provided a "true" habitat separation value, while using the mean +3 SD method produced a small effect size overestimate. Biased estimates of \%fwr affect estimates of the proportion of eels in a given habitat group, the proportion of residence in a given habitat, and the frequency of inter-habitat movement. The mean $+c S D$ method proposed provided HDCV values that differed by less than 0.5 units from that of the LDA method and thus a small effect size for estimates of \%fwr.

The frequency of movements between freshwater and estuarine habitats can be estimated from the number of transitions across the HDCV for groups of two or more contiguous $\mathrm{Sr}$ :Ca values, with a round trip comprising paired freshwater-to-estuarine and estuarine-to-freshwater transitions (Jessop et al., 2006, 2008). The nature of single Sr:Ca values deviating from the adjacent habitat norm is uncertain - they may represent actual habitat transitions or be technical artefacts (Tsukamoto and Arai, 2001; Jessop et al., 2006) but Panfili et al. (2012) conclude that they represent habitat transitions. Their inclusion when estimating \%fwr makes little difference but will affect counts of habitat transitions (Jessop et al., 2007). The application of smoothers to otolith Sr:Ca transect data is inappropriate if the mean $+c S D$ method is used to estimate a HDCV or when estimating frequency of habitat transition if singleton Sr:Ca values are believed to represent a habitat transition.

\subsection{Relation between HDCV, \%fwr, and growth rate}

The relation between growth rate and habitat salinity, represented by \%fwr, was strongly influenced by the choice of HDCV. The small to medium effect sizes of the HDCV value on this relation indicate the potential analytical and interpretive importance of an appropriate HDCV. However, the wide $\mathrm{CI}$ for the effect sizes, ranging from small to large values, reduces the interpretability of the effect sizes. An inappropriate HDCV choice, differing by as much as $0.5-1.0\left(\times 10^{-3}\right)$ from the appropriate value, may well result in misleading relations between growth rate and habitat salinity that have important biological implications. A HDCV bias of less than \pm 0.5 may have minor statistical and biological consequences.

The linkages between the process of calculating a HDCV, the methodology of estimating a HDCV, and the effect a HDCV has on the estimation of related but more biologically meaningful values such as the \%fwr and the relation between \%fwr and growth rate showed, over ranges of conditions that have occurred in reported studies, a progressive increase from trivial effect sizes to larger effect sizes. Medium to large effect sizes have been classified as analytically and biologically important (Arnquvist and Wooster, 1995; Kirk, 1996) and effect size may be associated with biological importance. However, the biological importance of an effect size must also be interpreted in relation to the nature of the study and the researcher's judgment (Cohen, 1988). The routine calculation of effect sizes in studies increases their value for later quantitative synthesis and analysis by meta-analysis for the further exploration of biological hypotheses and theoretical assumptions concerning the application of otolith $\mathrm{Sr}$ :Ca data (Arnquvist and Wooster, 1995; Ossenberg et al., 1999; Harrison, 2011).

\section{Conclusions}

In summary, (a) variable sample sizes for otolith Sr:Ca data may have little effect on the estimation of a freshwater-estuarine habitat separation (critical) value, although larger sample sizes are preferred, but the inclusion of estuarine $\mathrm{Sr}$ :Ca values from a short period of estuarine residence after the elver check increases the mean and variance of freshwater $\mathrm{Sr}$ :Ca values used to determine a HDCV, (b) LDA freshwater-estuarine habitat classification results can be duplicated, with the appropriate HDCV, in a spreadsheet, (c) the empirical relations of the mean $+c S D$ method may be used to estimate a HDCV when the LDA method is not applicable, (d) biased estimates of the HDCV, as may result from low otolith Sr:Ca sample sizes, may have important effects on subsequent interpretations of relations between habitat salinity and biological parameters such as \%fwr, the frequency of inter-habitat migration, and annual growth rate.

Good fishery management requires a better understanding of anguillid eel biology, including the proportions of an eel stock resident in habitats of varying salinity and the frequency and duration of inter-habitat movements. This study examines methods for the assessment of fish habitat residence and the classification of individual eels, and perhaps of other diadromous species, into habitat residence groups based on otolith $\mathrm{Sr}$ :Ca data. 


\section{Acknowledgments}

We thank M. Feigenbaum and M. Campbell for providing the eel samples and for use of the facilities at South Shore Trading Company Ltd. Thanks also to S. Stewart for statistical advice and to G. Bareille, I. Thibault, J.-C. Shiao, and W. Morrison for information supplemental to their publications.

\section{References}

Arai, T., Kotake, A., Lokman, P.M., Miller, M.J., Tsukamoto, K., 2004. Evidence of different habitat use by New Zealand freshwater eels, Anguilla australis and A. dieffenbachii, as revealed by otolith microchemistry. Marine Ecology Progress Series 266, 213-225.

Arnquvist, G., Wooster, D., 1995. Meta-analysis: synthesizing research findings in ecology and evolution. Tree 10, 236-240.

Berry, D.A., 1987. Logarithmic transformations in ANOVA. Biometrics 43, 439-456.

Bradbury, I.R., DiBacco, C., 2011. Resolving natal tags using otolith geochemistry in an estuarine fish, rainbow smelt Osmerus mordax. Marine Ecology Progress Series 433, 195-204. http://dx.doi.org/10.3354/meps09178.

Bradbury, I.R., Campana, S.E., Bentzen, P., 2008. Otolith elemental composition and adult tagging reveal spawning site fidelity and estuarine dependency in rainbow smelt. Marine Ecology Progress Series 368, 255-268.

Brown, J.A., 2006. Classification of juvenile flatfishes to estuarine and coastal habitats based on the elemental composition of otoliths. Estuarine, Coastal and Shelf Science 66, 594-611.

Brown, J.R., Severin, K.P., 2009. Otolith chemistry analyses indicate that water Sr:Ca is the primary factor influencing otolith $\mathrm{Sr}$ :Ca for freshwater and diadromous fish but not for marine fish. Canadian Journal of Fisheries and Aquatic Sciences $66,1790-1808$

Cairns, D.K., Shiao, J.-C., Iizuka, Y., Tzeng, W.-N., MacPherson, C.D., 2004. Movement patterns of American eels in an impounded watercourse, as indicated by otolith microchemistry. North American Journal of Fishery Management 24, 452-458.

Campana, S.E., 1999. Chemistry and composition of fish otoliths: pathways, mechanisms and applications. Marine Ecology Progress Series 188, 263-297.

Chino, N., Arai, T., 2010a. Occurrence of marine resident tropical eel Anguilla bicolor bicolor in Indonesia. Marine Biology 157, 1075-1081.

Chino, N., Arai, T., 2010b. Habitat use and habitat transitions in the tropical eel, Anguilla bicolor bicolor. Environmental Biology of Fishes 89, 571-578.

Chino, N., Arai, T., 2010c. Migratory history of the giant mottled eel (Anguilla marmorata) in the Bonin Islands of Japan. Ecology of Freshwater Fish 19, 19-25.

Cohen, J., 1988. Statistical Power Analysis for the Behavioral Sciences, second ed. Erlbaum, Hillsdale, New Jersey. 590 pp.

D’Agostino, R.B., Belanger, A., D’Agostino Jr., R.B., 1990. A suggestion for using powerful and informative tests of normality. American Statistician 44, 316-321.

Daverat, F., Tomás, J., 2006. Tactics and demographic attributes in the European eel Anguilla anguilla in the Gironde watershed, SW France. Marine Ecology Progress Series 307, 247-257.

Daverat, F., Tomas, J., Lahaye, M., Palmer, M., Elie, P., 2005. Tracking continental habitat shifts of eels using otolith $\mathrm{Sr} / \mathrm{Ca}$ ratios: validation and application to the coastal, estuarine and riverine eels of the Gironde-Garonne-Dordogne watershed. Marine and Freshwater Research 56, 619-627.

Daverat, F., Limburg, K.E., Thibault, I., Shiao, J.-C., Dodson, J.J., Caron, F., Tzeng, W.-N., Iizuka, Y., Wickström, H., 2006. Phenotypic plasticity of habitat use by three temperate eel species, Anguilla anguilla, A. japonica and A. rostrata. Marine Ecology Progress Series 308, 231-241.

de Villiers, S., 1999. Seawater strontium and Sr/Ca variability in the Atlantic and Pacific Oceans. Earth and Planetary Science Letters 171, 623-634.

de Vries, M.C., Gillanders, B.M., Elsdon, T.S., 2005. Facilitation of barium uptake into fish otoliths: influence of strontium concentration and salinity. Geochimica et Cosmochimica Acta 69 (16), 4061-4072.

Dutil, J.-D., Michaud, M., Giroux, A., 1989. Seasonal and diel patterns of stream invasion by American eels (Anguilla rostrata) in the northern Gulf of St. Lawrence. Canadian Journal of Zoology 67, 182-188.

Elsdon, T.S., Gillanders, B.M., 2005. Alternative life-history patterns of estuarine fish: barium in otoliths elucidates freshwater residency. Canadian Journal of Fisheries and Aquatic Sciences 62, 1143-1152.

Elsdon, T.S., Wells, B.K., Campana, S.E., Gillanders, B.M., Jones, C.M., Limburg, K.E., Secor, D.H., Thorrold, S.R., Walther, B.D., 2008. Otolith chemistry to describe movements and life-history parameters of fishes: hypotheses, assumptions, limitations and inferences. Oceanography and Marine Biology: An Annual Review 46, 297-330.

Fablet, R., Daverat, F., De Pontual, H., 2007. Unsupervised Bayesian reconstruction of individual life histories from otolith signatures: a case study of Sr:Ca transects of European eel (Anguilla anguilla) otoliths. Canadian Journal of Fisheries and Aquatic Sciences 64, 152-165.

Gillanders, B.M., Kingsford, M.J., 2000. Elemental fingerprints of otoliths of fish may distinguish estuarine "nursery" habitats. Marine Ecology Progress Series 201, $273-286$.

Hair, J.F., Anderson, R.E., Tatham, R.L., Black, W.C., 1998. Multivariate Data Analysis, fifth ed. Prentice Hall, Englewoods Cliffs, New York. 768 pp.
Hale, R., Swearer, S.E., 2008. Otolith microstructural and microchemical changes associated with settlement in the diadromous fish Galaxias maculates. Marine Ecology Progress Series 354, 229-234.

Harrison, F., 2011. Getting started with meta-analysis. Methods in Ecology and Evolution 2, 1-10.

Hedger, R.D., Atkinson, P.M., Thibault, I., Dodson, J.J., 2008. A quantitative approach for classifying fish otolith strontium:calcium sequences into environmental histories. Ecological Informatics 3, 207-217.

Huberty, C., Olejnik, S., 2006. Applied MANOVA and Discriminant Analysis, second ed. John Wiley \& Sons, Hoboken, New Jersey. 524 pp.

Jessop, B.M., 2010. Geographic effects on American eel (Anguilla rostrata) life history characteristics and strategies. Canadian Journal of Fisheries and Aquatic Sciences 67, 326-346.

Jessop, B.M., Shiao, J.-C., Iizuka, Y., Tzeng, W.-N., 2002. Migratory behaviour and habitat use by American eels Anguilla rostrata as revealed by otolith microchemistry. Marine Ecology Progress Series 233, 217-229.

Jessop, B.M., Shiao, J.-C., Iizuka, Y., Tzeng, W.-N., 2004. Variation in the annua growth, by sex and migration history, of silver American eels Anguilla rostrata. Marine Ecology Progress Series 272, 231-244.

Jessop, B.M., Shiao, J.-C., Iizuka, Y., Tzeng, W.-N., 2006. Migration of juvenile American eels Anguilla rostrata between freshwater and estuary, as revealed by otolith microchemistry. Marine Ecology Progress Series 310, 219-233.

Jessop, B.M., Shiao, J.-C., Iizuka, Y., Tzeng, W.-N., 2007. Effects of inter-habitat migration on the evaluation of growth rate and habitat residence of American eels Anguilla rostrata. Marine Ecology Progress Series 342, 255-263.

Jessop, B.M., Cairns, D.K., Thibault, I., Tzeng, W.N., 2008. Life history of American eel Anguilla rostrata: new insights from otolith microchemistry. Aquatic Biology 1 205-216.

Jessop, B.M., Shiao, J.C., Iizuka, Y., 2009. Life history of American eels from western Newfoundland. Transactions of the American Fisheries Society 138, 861-871.

Jessop, B.M., Wang, C.H., Tzeng, W.N., You, C.F., Shiao, J.C., Lin, S.H., 2011. Otolith Sr: $\mathrm{Ca}$ and $\mathrm{Ba}: \mathrm{Ca}$ may give inconsistent indications of estuarine habitat use for American eels (Anguilla rostrata). Environmental Biology of Fishes 93, 193-207. http://dx.doi.org/10.1007/s10641-011-9905-0.

Kawakami, Y., Mochioka, N., Morishita, K., Tajima, T., Nakagawa, H., Toh, H. Nakazono, A., 1998. Factors influencing otolith strontium/calcium ratios in Anguilla japonica elvers. Environmental Biology of Fishes 52, 299-303.

Kirk, R.E., 1996. Practical significance: a concept whose time has come. Educational and Psychological Measurement 56, 746-759.

Kotake, A., Arai, T., Ozawa, T., Nojima, S., Miller, M.J., Tsukamoto, K., 2003. Variation in migratory history of Japanese eels, Anguilla japonica, collected in coasta waters of the Amakusa Islands, Japan, inferred from otolith $\mathrm{Sr} / \mathrm{Ca}$ ratios. Marine Biology 142, 849-854.

Kotake, A., Arai, T., Ohji, M., Yamane, S., Miyazaki, N., Tsukamoto, K., 2004. Application of otolith microchemistry to estimate the migratory history of Japanese eel Anguilla japonica on the Sanriku Coast of Japan. Journal of Applied Ichthyology 20, 150-153.

Kotake, A., Okamura, A., Yamada, Y., Utoh, T., Arai, T., Miller, M.J., Oka, H.P. Tsukamoto, K., 2005. Seasonal variation in the migratory history of the Japanese eel Anguilla japonica in Mikawa Bay, Japan. Marine Ecology Progress Series 293 213-221.

Kraus, R.T., Secor, D.H., 2004. Incorporation of strontium into otoliths of an estuarine fish. Journal of Experimental Marine Biology and Ecology 302, 85-106.

Lamson, H.M., Shiao, J.-C., Iizuka, Y., Tzeng, W.-N., Cairns, D.K., 2006. Movement patterns of American eels (Anguilla rostrata) between salt- and freshwater in coastal watershed, based on otolith microchemistry. Marine Biology 149, 15671576.

Le, D.Q., Chino, N., Shirai, K., Arai, T., 2010. Trace metals in Japanese eel Anguilla japonica in relation to ecological migratory types and growth stages. Estuarine Coastal and Shelf Science 87, 405-410.

Lin, S.-H., Chang, C.-W., Iizuka, Y., Tzeng, W.-N., 2007. Salinities, not diets, affect strontium/calcium ratios in otoliths of Anguilla japonica. Journal of Experimental Marine Biology and Ecology 341, 254-263.

Lin, Y.-J., Yalçin-Özdilek, S., Iizuka, Y., Gümüs, A., Tzeng, W.-N., 2011. Migratory life history of European eel Anguilla anguilla from freshwater regions of the River Asi, southern Turkey and their high otolith Sr:Ca ratios. Journal of Fish Biology $78,860-868$.

Lin, S.H., Iizuka, Y., Tzeng, W.-N., 2012. Migration behavior and habitat use by juvenile Japanese eels Anguilla japonica in continental waters as indicated by mark-recapture experiments and otolith microchemistry. Zoological Studies 51, 442-452.

Lipsey, M.W., Wilson, D.B., 2001. Practical Meta-analysis. Sage, Beverly Hills, CA.

Macdonald, J.I., Crook, D.A., 2010. Variability in Sr:Ca and Ba:Ca ratios in water and fish otoliths across an estuarine salinity gradient. Marine Ecology Progress Series 413, 147-161.

Martínez-Abraín, A., 2008. Statistical significance and biological relevance: a call for a more cautious interpretation of results in ecology. Acta Oecologica 34, 9-11.

McCulloch, M., Cappo, M., Aumend, J., Müller, W., 2005. Tracing the life history of individual barramundi using laser ablation MC-ICP-MS Sr-isotopic and Sr/Ba ratios in otoliths. Marine and Freshwater Research 56, 637-644.

Melià, P., Bevacqua, D., Crivelli, A.J., Panfili, J., De Leo, G.A., Gatto, M., 2006. Sex differentiation of the European eel in brackish and freshwater environments: a comparative analysis. Journal of Fish Biology 69, 1228-1235.

Moran, M., 2003. Arguments for rejecting the sequential Bonferroni in ecological studies. Oikos 100, 403-405. 
Morrison, W.E., Secor, D.H., Piccoli, P.M., 2003. Estuarine habitat use by Hudson River American eels as determined by strontium:calcium ratios. In: Dixon, D.A. (Ed.), Biology, Management, and Protection of Catadromous Eels. American Fishery Society, Bethesda, Maryland, pp. 87-99. Symposium 33.

Nakagawa, S., 2004. A farewell to Bonferroni: the problems of low statistical power and publication bias. Behavioral Ecology 15, 1044-1045.

Nakagawa, S., Cuthill, I.C., 2007. Effect size, confidence interval and statistical significance: a practical guide for biologists. Biological Review 82, 591-605.

Ossenberg, C.W., Sarnelle, O., Cooper, S.D., Holt, R.D., 1999. Resolving ecological questions through meta-analysis: goals, metrics, and models. Ecology 80, 1105-1117.

Panfili, J., Darnaude, A.M., Lin, Y.-J., Chevalley, M., Iizuka, Y., Tzeng, W.-N. Crivelli, A.J., 2012. Habitat residence during continental life of the European eel (Anguilla anguilla) investigated using linear discriminant analysis applied to otolith Sr:Ca ratios. Aquatic Biology 15, 175-185.

Phillis, C.C., Ostrach, D.J., Ingram, B.L., Weber, P.K., 2011. Evaluating otolith Sr:Ca as a tool for reconstructing estuarine habitat use. Canadian Journal of Fisheries and Aquatic Sciences 68, 360-373.

R Development Core Team, 2011. R: A Language and Environment for Statistical Computing, Reference Index Version 2.12.1. R Foundation for Statistical Computing, Vienna, Austria. http://www.R-project.org.

Rosenthal, R., 1993. Cumulating evidence. In: Keren, G., Lewis, C. (Eds.), A Handbook for Data Analysis in the Behavioural Sciences: Methodological Issues. Erlbaum, Hillsdale, New Jersey, pp. 519-559.

Secor, D.H., Rooker, J.R., 2000. Is otolith strontium a useful scalar of life cycles in estuarine fishes? Fisheries Research 46, 359-371.

Secor, D.H., Henderson-Arzapalo, A., Piccoli, P.M., 1995. Can otolith microchemistry chart patterns of migration and habitat utilization in anadromous fishes? Journal of Experimental Marine Biology and Ecology 192, 15-33.

Shiao, J.C., Ložys, L., Iizuka, Y., Tzeng, W.N., 2006. Migratory patterns and contributions of stocking to the population of European eels in Lithuanian waters as indicated by otolith Sr:Ca ratios. Journal of Fish Biology 69, 749-769.

Sokal, R.R., Rohlf, F.J., 1981. Biometry, second ed. WH Freeman and Company, New York. 859 pp.

Tabouret, H., Bareille, G, Claverie, F, Pécheyran, C, Prouzet, P. Donard, O.FX, 2010. Simultaneous use of strontium:calcium and barium:calcium ratios in otoliths as markers of habitat: application to the European eel (Anguilla anguilla) in the Adour basin, South West France. Marine Environmental Research 70, 35-45.

Tatsuoka, M., 1993. Effect size. In: Keren, G., Lewis, C. (Eds.), A Handbook for Data Analysis in the Behavioural Sciences: Methodological Issues. Erlbaum, Hillsdale, New Jersey, pp. 461-479.
Thibault, I., Dodson, J.J., Caron, F., Tzeng, W.-N., Iizuka, Y., Shiao, J.-C., 2007. Facultative catadromy in American eels: testing the conditional strategy hypothesis. Marine Ecology Progress Series 344, 219-229.

Tsukamoto, K., Arai, T., 2001. Facultative catadromy of the eel Anguilla japonica between freshwater and seawater habitats. Marine Ecology Progress Series 220, 265-276.

Tzeng, W.-N., 1996. Effects of salinity and ontogenetic movements on strontium: calcium ratios in the otoliths of the Japanese eel, Anguilla japonica Temminck and Schlegel. Journal of Experimental Marine Biology and Ecology 199, 111-122.

Tzeng, W.N., Severin, K.P., Wickström, H., 1997. Use of otolith microchemistry to investigate the environmental history of European eel Anguilla anguilla. Marine Ecology Progress Series 149, 73-81.

Tzeng, W.N., Wang, C.H., Wickström, H., Reizenstein, M., 2000. Occurrence of the semi-catadromous European eel Anguilla anguilla in the Baltic Sea. Marine Biology 137, 93-98.

Tzeng, W.N., Shiao, J.C., Iizuka, Y., 2002. Use of otolith Sr:Ca ratios to study the riverine migratory behaviours of the Japanese eel Anguilla japonica. Marine Ecology Progress Series 245, 213-221.

Tzeng, W.N., Severin, K.P., Wang, C.H., Wickström, H., 2005. Elemental composition of otoliths as a discriminator of life stage and growth habitat of the European eel, Anguilla anguilla. Marine and Freshwater Research 56, 629-635.

Venables, W.N., Ripley, B.D., 2002. Modern Applied Statistics with S, fourth ed. Springer, New York. 504 pp.

Walther, B., Thorrold, S.R., 2008. Continental-scale variation in otolith geochemistry of juvenile American shad (Alosa sapidissima). Canadian Journal of Fisheries and Aquatic Sciences 65, 2623-2635.

Walther, B.D., Limburg, K.E., 2012. The use of otolith chemistry to characterize diadromous migrations. Journal of Fish Biology 81, 796-825.

Zar, J.H., 1984. Biostatistical Analysis, second ed. Prentice-Hall, Englewood Cliffs, New Jersey.

Ziegler, J.M., Whitledge, G.W., 2010. Assessment of otolith chemistry for identifying source environment of fishes in the lower Illinois River, Illinois. Hydrobiologia 638, 109-119. http://dx.doi.org/10.1007/s10750-009-0033-1.

Zimmerman, C.E., 2005. Relationship of otolith strontium-to-calcium ratios and salinity: experimental validation for juvenile salmonids. Canadian Journal of Fisheries and Aquatic Sciences 62, 88-97.

Zuur, A.F., Ieno, E.N., Smith, G.M., 2007. Analyzing Ecological Data. Springer, New York, $672 \mathrm{pp}$. 